\title{
CrystEngComm
}

CrossMark

$\leftarrow$ click for updates

Cite this: CrystEngComm, 2015, 17, 3153

Received 5th December 2014, Accepted 8th March 2015

DOI: $10.1039 / c 4 c e 02413 c$

www.rsc.org/crystengcomm

\section{Conformational adaptations of acyclic receptor templated by weakly coordinating anions $\uparrow$}

\author{
I. Đilović*a and K. Užarevićt *b
}

\begin{abstract}
Crystallization from methanol solutions resulted in new supramolecular complexes of a flexible polyamine receptor N,N'-3-azapentane-1,5-bis[3-(1-aminoethylidene)-6-methyl-3H-pyran-2,4-dione] (L) with spherical $\left(\mathrm{Br}^{-}\right.$and $\left.\mathrm{I}^{-}\right)$, linear $\left(\mathrm{SCN}^{-}\right)$or pyramidal $\left(\mathrm{ClO}_{3}^{-}\right)$anions. The recognition and self-assembly processes yielded five solids: solvated (1a) and non-solvated (1b) forms of $\mathrm{HL}: \mathrm{SCN}^{-}$complex with quite different receptor conformations, a supramolecular complex with $\mathrm{ClO}_{3}^{-}$anion (3), which is isoskeletal to $1 \mathrm{~b}$, and $\mathrm{HL}: \mathrm{Br}^{-}$(2) and $\mathrm{HL}: I^{-}$complexes which are isoskeletal to $1 \mathrm{a}$. It is shown that the rich coordinating potential of the anions investigated arises not only from their geometry but also from their ambivalent accepting functionalities. The divergence in the way binding occurs is reflected on supramolecular synthons stabilizing crystal structures as well as on the physicochemical properties of the obtained solids. In these systems, anion binding could be interpreted as a competition between two "solvation spheres", one provided by the solvent molecules and the other dominated by high-order supramolecular receptors built from HL molecules. This behaviour is related to previously reported complexes of HL with trigonal, tetrahedral and octahedral anions, emphasizing the receptor's conformational adaptability for providing the most favourable surrounding for guest inclusion in the rigid environment of a crystal.
\end{abstract}

\section{Introduction}

The design of artificial receptors which are able to recognize, bind, sense and/or transport guest molecules is attracting increasing attention. ${ }^{1}$ A great variety of preorganized and rigid anion receptors has been studied, as these systems often display high peak selectivity in solution. ${ }^{2}$ The second class of often studied receptors comprises those with the ability to change their conformation in order to respond to the specific demands of the anionic template (geometry, charge density, pH-dependent behaviour, etc.). ${ }^{3}$ These receptors often have lower binding constants in contrast to their rigid analogues, but they showed strong potential in the development of various functional supramolecular systems, ${ }^{4}$ from sensors and signallers ${ }^{5}$ to more effective rigid receptors. ${ }^{6}$ In this context, the study of the interaction modes between the flexible receptor and flexible or multifaceted anions (such as linear thiocyanate or pyramidal chlorate) could prove especially interesting and lead to further developments in the field. ${ }^{7-10}$

\footnotetext{
${ }^{a}$ Department of Chemistry, Faculty of Science, University of Zagreb, Horvatovac 102a, 10000 Zagreb, Croatia.E-mail: idilovic@chem.pmf.hr

${ }^{b}$ Ruđer Bošković Institute, Division of Physical Chemistry, Bijenička 54, 10002 Zagreb, Croatia. E-mail: Krunoslav.Uzarevic@irb.hr

$\dagger$ Electronic supplementary information (ESI) available. CCDC 978263-978265, 1035947 and 1051952. For ESI and crystallographic data in CIF or other electronic format see DOI: 10.1039/c4ce02413c

\$ Current address: McGill University, Department of Chemistry, 801 Sherbrooke St. West, Montreal, QC H3A 0B8, Canada.
}
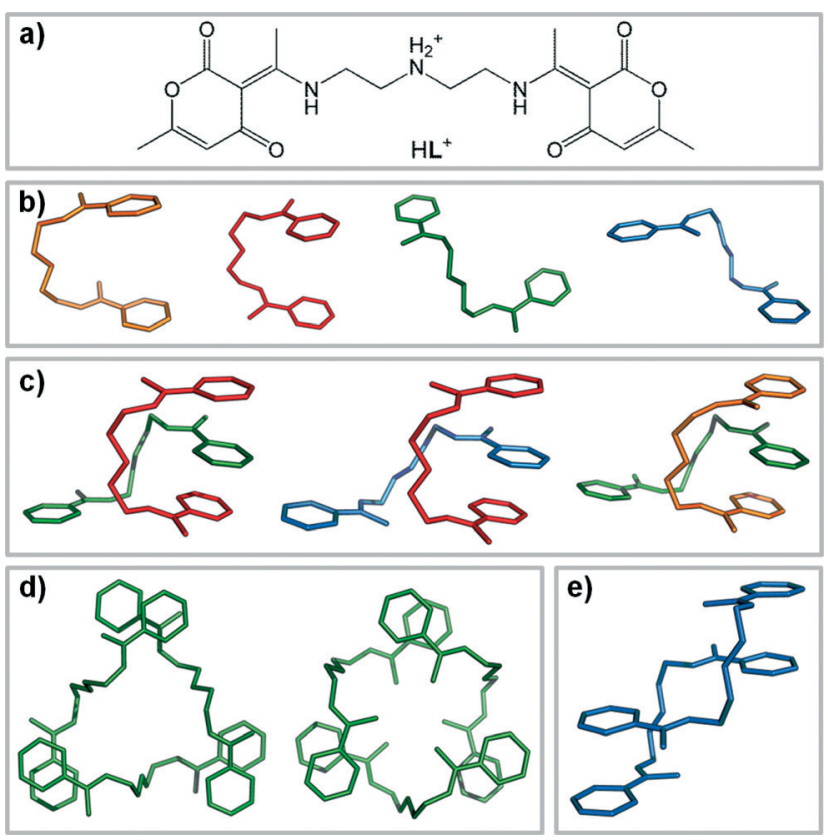

Scheme 1 (a) Protonated polyamine receptor HL. (b) In complexes with anions, $\mathrm{HL}$ adopts different conformers depending on the relative orientation of methyl groups - syn-C (orange), anti-C (red), syn-Z (green) and anti-Z (blue). The conformers assemble in high-order supramolecular receptors [as in (c) or (d)] or supramolecular polymers [in (e)]. Hydrogen atoms and anions were omitted for clarity. 
In our recent studies of binding of environmentally relevant anions, flexible polyamine receptor HL (Scheme 1a) was found to display a remarkable adaptability towards diverse inorganic or organic anions, with high peak selectivity for hydrogen maleate, sulphate and nitrate. ${ }^{11-13}$ Two principal sets of the receptor conformations were observed in the obtained crystal structures, denoted as C- and Z-conformers (Scheme 1b). Occasionally, a single HL molecule served as a receptor for a single anion (hydrogen maleate or $o$-phthalate), but more often, HL cations assembled to supramolecular receptors, in order to achieve complementarity for specific anion(s). The observed supramolecules include discrete CZdimers, various Z-trimers and supramolecular polymers (Scheme 1c-e). Hydrophilic anions (trigonal $\mathrm{NO}_{3}{ }^{-}$and tetrahedral $\mathrm{SO}_{4}{ }^{2-}$ ) were excluded from the competitive mixtures by the self-assembly of three HL molecules into a pseudomacrocycle, with the anion encapsulated inside the formed receptor supramolecule by 12 strong $\mathrm{N}-\mathrm{H} \cdots \mathrm{O}$ hydrogen bond interactions (Scheme 1d, left). ${ }^{11}$ On the other hand, perchlorate anion $\left(\mathrm{ClO}_{4}{ }^{-}\right)$, which is geometrically identical to sulphate but with a lower charge density, templates the selfassembly of three HL cations into a new supramolecular receptor with vacant interior, and the binding is achieved by weak $\mathrm{C}-\mathrm{H}$ donor groups (Scheme 1d, right). ${ }^{12 a}$ The same binding mode was found for other hydrophobic anions $\left(\mathrm{HSO}_{3}{ }^{-}, \mathrm{IO}_{4}{ }^{-}, \mathrm{PF}_{6}{ }^{-}, \mathrm{SbF}_{6}{ }^{-}\right)$which were encapsulated in similar hydrophobic pockets of the emerged crystal structure. ${ }^{12 a}$ In the systems studied, ${ }^{11,12} \mathrm{HL}$ proved highly sensitive to the geometry and charge density of the anionic guest. Selectivity in separation has usually been achieved only upon crystallization, emphasizing the importance of intermolecular interactions in the rigid crystal environment which lock the conformation of the host. The same supramolecular concept was also transferred to solvent-free mechanochemical discrimination between isomeric organic acids. ${ }^{13}$

Herein we study the complexation modes of the receptor HL with spherical $\left(\mathrm{Br}^{-}\right.$and $\left.\mathrm{I}^{-}\right)$and multifaceted linear $\left(\mathrm{SCN}^{-}\right)$or pyramidal $\left(\mathrm{ClO}_{3}{ }^{-}\right)$anions. The structural investigations on two forms of $\mathrm{HL}: \mathrm{SCN}^{-}$complexes (1a and 1b) have shown that neither anion geometry nor the overall charge is decisive for the final folding mode of the receptor. The results indicate that the types of accepting groups on the anion also play an important role in the occurring type of complex. The interplay between anion coordination ambivalence and receptor conformational/binding versatility results in different host-guest interactions and supramolecular architectures, where the receptor molecules assemble to polymeric chains (as in $1 \mathrm{a}$ and 2 - with $\mathrm{SCN}^{-}, \mathrm{Br}^{-}$and $\mathrm{I}^{-}$) or dimers (1b and $3-$ with $\mathrm{SCN}^{-}$and $\mathrm{ClO}_{3}{ }^{-}$). To rationalize our structural observations, detailed overview of the Cambridge Structural Database $(\mathrm{CSD})^{14}$ and Protein Data Bank (PDB) ${ }^{15}$ was made, and the results were compared with already known host/protein and $\mathrm{SCN}^{-}$supramolecular complexes.

\section{Results and discussion}

Crystalline products $\mathbf{1 a}$ and $\mathbf{1 b}$ were obtained from the selfassembly between $\mathbf{L}$ and ammonium thiocyanate in acidified methanol (both 1a and 1b) or ethanol (1b exclusively) solutions. From methanol, the occurrence of the respective phase was related to the time needed for crystallization. The slow evaporation and prolonged duration of crystallization resulted in exclusive occurrence of the solvated phase, 1a, whereas the fast crystallization from highly concentrated methanol solutions yielded $\mathbf{1 b}$. From ethanol, crystallization would proceed swiftly (in a matter of minutes) and $\mathbf{1 b}$ was harvested in all cases. Reactions were also attempted in acetonitrile and acetone, where the ligand, $\mathrm{NH}_{4} \mathrm{SCN}$ and $p$-toluenesulfonic acid are readily soluble. However, from these solvents solid ammonium $p$-toluenesulfonate was obtained. Complexes with bromide and chlorate anions, 2 and 3 respectively, were obtained by reacting equimolar amounts of $\mathbf{L}$ and $\mathrm{HBr}$ or $\mathrm{HClO}_{3}$ in methanol. Colourless crystals of forms 1a, 2 and 3 desolvated and fell apart in air, while $1 \mathrm{~b}$ was stable, even at $80{ }^{\circ} \mathrm{C}$. The complex of $\mathrm{HL}$ with iodide anions was prepared by a procedure similar to 1a, but the obtained crystals were not suitable to conduct a thorough structural analysis and will therefore be excluded from detailed discussion. However, the derived structural model was sufficient to establish the unit cell parameters and the arrangement of the receptor molecules, which is very similar to that of the bromide complex 2 and the 1 a form of the $\mathrm{SCN}^{-}$complex. The IR spectra of bromide and iodide complexes are in a good agreement, further suggesting that the same supramolecular synthon is present in the solid phase (for more details, please refer to the $\mathrm{ESI} \dagger$ ).

\section{Crystal structure description}

In four crystal structures, three distinguishable HL conformers were found (Tables 1 and 2). In $\mathbf{1 b}$ and 3, syn-C and syn-Z conformers assemble to CZ-dimers which are favorable

Table 1 Aliphatic chain torsion angles (absolute values) in degrees ${ }^{a}$

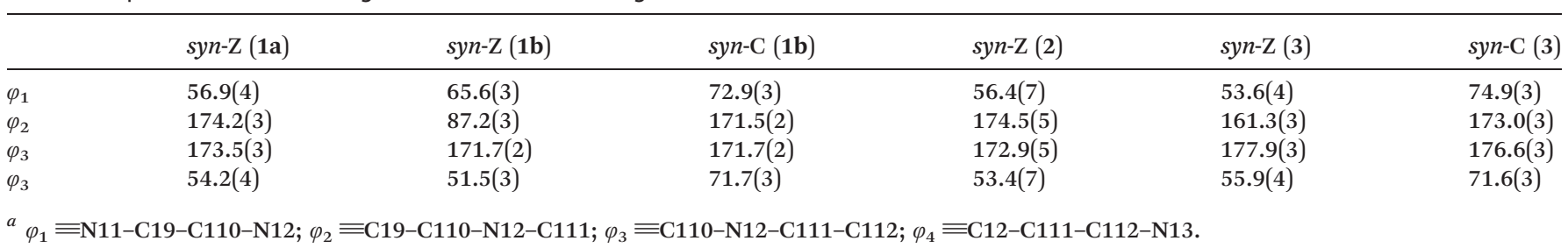


Table 2 Crystal data and structure refinements parameters for 1a, 1b, 2 and 3

\begin{tabular}{|c|c|c|c|c|}
\hline & $1 \mathrm{a}$ & $1 \mathbf{b}$ & 2 & 3 \\
\hline Crystal size $\left(\mathrm{mm}^{3}\right)$ & $0.15 \times 0.12 \times 0.10$ & $0.21 \times 0.18 \times 0.15$ & $0.30 \times 0.10 \times 0.03$ & $0.25 \times 0.22 \times 0.13$ \\
\hline Space group & $P \overline{1}$ & $C 2 / c$ & $P \overline{1}$ & $P 2_{1} / n$ \\
\hline \multicolumn{5}{|l|}{ Unit cell dimensions } \\
\hline$a(\AA)$ & $8.0072(5)$ & $33.554(7)$ & 7.9370(5) & 15.9465(6) \\
\hline$b(\AA)$ & $11.8432(9)$ & $13.996(3)$ & $12.8236(10)$ & $18.9851(4)$ \\
\hline$\beta\left({ }^{\circ}\right)$ & $106.07(6)$ & $100.54(3)$ & $76.806(6)$ & $111.55(1)$ \\
\hline$\gamma\left({ }^{\circ}\right)$ & $97.869(6)$ & 90.00 & $78.841(6)$ & 90.00 \\
\hline Volume $\left(\AA^{3}\right)$ & $1188.2(1)$ & $8608(3)$ & $1298.1(1)$ & $4862.2(3)$ \\
\hline$Z$ & 2 & 16 & 2 & 4 \\
\hline$D_{\text {calc }}\left(\mathrm{g} \mathrm{cm}^{-3}\right)$ & 1.382 & 1.428 & 1.249 & 1.473 \\
\hline$\mu\left(\mathrm{mm}^{-1}\right)$ & 0.187 & 0.198 & 1.669 & 0.223 \\
\hline$R / \mathrm{w} R[I>2 \sigma(I)]^{a}$ & $0.0732 / 0.1353$ & $0.0481 / 0.0749$ & $0.1041 / 0.3058$ & $0.0665 / 0.1859$ \\
\hline$R / \mathrm{w} R$ [all data] & $0.1560 / 0.1589$ & $0.0872 / 0.1291$ & $0.1452 / 0.3386$ & $0.0816 / 0.1971$ \\
\hline Goodness-of-fit on $F^{2}$ & 0.970 & 0.841 & 1.161 & 1.033 \\
\hline Largest diff. peak and hole $\left(\mathrm{e} \AA^{-3}\right)$ & $0.639,-0.387$ & $0.297,-0.322$ & $1.146,-0.902$ & $1.192,-0.538$ \\
\hline
\end{tabular}

for anion binding [Scheme 1c (far right) and Fig. 2]. In 1a and 2 , on the other hand, syn-Z conformers occur exclusively, building $[s y n-Z \cdots s y n-Z]_{n}$ supramolecular polymers through the rich pattern of noncovalent interactions. The key structural parameters (bond lengths, hydrogen-bonding geometry) are given in Tables S1-S8 in the ESI. $\dagger$

\section{Supramolecular polymers for anion exclusion}

In complexes with $\mathrm{SCN}^{-}$(1a) and $\mathrm{Br}^{-}$(2), exclusively syn-Z conformers self-assemble to a new kind of polymeric host for a complexation of $\mathrm{SCN}^{-}$and $\mathrm{Br}^{-}$anions (Fig. 1). The central amino $-\mathrm{NH}_{2}{ }^{+}$group acts as a HB-bridge between two distinct pyrone oxygen atoms [O1 and O4, 2.715(4) and 2.698(4) $\AA$, respectively] in a one-dimensional chain. Neighbouring chains are further connected by the N1-H1 $\cdots \mathrm{O} 3[3.042(4) \AA]$

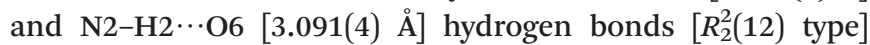
and pyrone $\pi \cdots \pi$ interactions [3.454(2) and 3.265(2) $\AA$ ]. This layer-like arrangement of HL molecules saturates the strong $\mathrm{N}-\mathrm{H}$ donors and creates large $\mathrm{C}-\mathrm{H}$ rich "walls", parallel to the crystallographic ac plane, in which the anions are accommodated. These hydrophobic regions are also occupied by the solvent methanol molecules which anchor the $\mathrm{SCN}^{-}$by

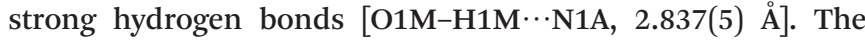
other side of $\mathrm{SCN}^{-}$is coordinated using preferentially weaker $\mathrm{C}-\mathrm{H} \cdots \mathrm{S} 1 \mathrm{~A}$ and $\mathrm{C}-\mathrm{H} \cdots \mathrm{C} 1 \mathrm{~A}$ interactions from HL. A picture emerges in which anion binding could be interpreted as a competition between two "solvation spheres", one provided by the solvent molecule and the other dominated by highly ordered supramolecular receptors built from HL cations. The
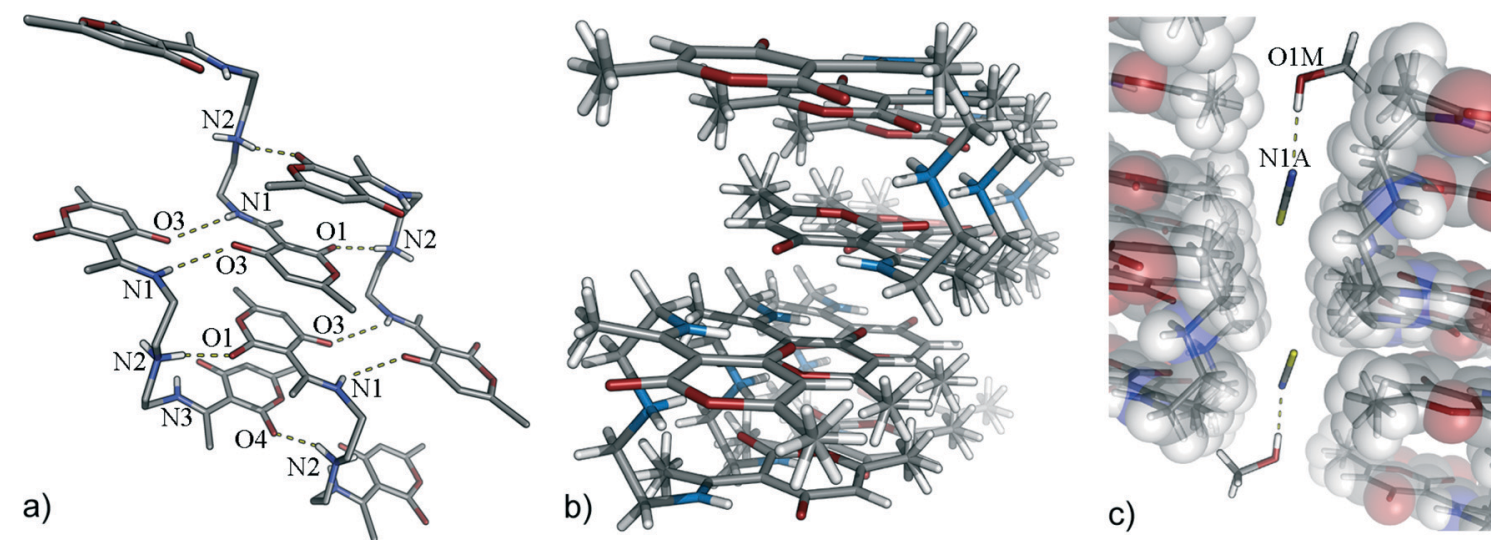

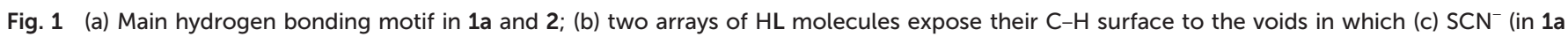
are shown) or $\mathrm{Br}^{-}$(2) anions and methanol molecules are placed (a perspective view). Hydrogen atoms which are not participating in the hydrogen bonding are omitted for clarity. 
bromide complex 2 is isostructural to 1 a (for details, please see the experimental section).

\section{Anion encapsulation by CZ-dimers}

In both crystal structures $\mathbf{1 b}$ and $\mathbf{3}$, dimers are made of syn-C and syn-Z conformers constructing interpenetrating chains (mutually held by $\mathrm{C}-\mathrm{H} \cdots \mathrm{O}$ and $\mathrm{C}-\mathrm{H} \cdots \pi$ interactions) which are capable of encapsulating anions in the emerged voids (Fig. 2). In a single chain of $1 \mathbf{b}$, syn-C conformers act as $\pi$-molecular tweezers for syn-Z conformers, which are anchored by a strong charge-assisted hydrogen bond [N22-

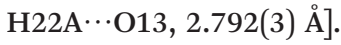

It seems again ${ }^{13}$ that the formation of tweezers is advantageous for planar $\mathrm{HB}$-acceptors. The central $-\mathrm{NH}_{2}{ }^{+}$group is the best donor and with the best acceptor (pyrone 013-atom) forms a short intermolecular hydrogen bond, while the receptor supermolecule is completed through pyrone $\pi \cdots \pi$ interactions [3.56(1) and 3.55(1) Å]. In 1b, a second hydrogen atom of the $-\mathrm{NH}_{2}{ }^{+}$group acts as a bifurcated hydrogen bond donor towards the nitrogen atom of $\mathrm{SCN}^{-}$[2.914(15) $\AA$ ] and $\mathrm{O} 11$ $[2.889(3) \AA]$ of the other Z-conformer. In the Z-conformers, the central $-\mathrm{NH}_{2}{ }^{+}$group forms hydrogen bonds with $\mathrm{O} 26$ [2.881(3) $\AA]$ atoms from C-conformers and nitrogen atoms (N31) of other $\mathrm{SCN}^{-}$anions [2.688(3) $\AA$ ]. It is also important to address how the SC-part, particularly the S-atomic part, of the $\mathrm{SCN}^{-}$is accommodated in a highly complementary environment within the crystal, i.e. in $\mathrm{C}-\mathrm{H}$ rich surfaces inside the crystal structure. The other sulphur atom of the crystallographically independent $\mathrm{SCN}^{-}$, in addition to the $\mathrm{C}-\mathrm{H}$ region, is embraced by the $\pi$-systems of two neighbouring pyrone moieties [3.36(1) $\AA$ from the Z-conformer and 3.34(1) $\AA$ from the C-conformer, Fig. 4].

It is interesting to note that, when the main interaction of the receptor is with the weaker hydrogen-bonding acceptor group of the thiocyanate, the receptor self-assembles to form a high-ordered supramolecule (polymer) in order to saturate its strong hydrogen-bonding donor groups and uses only weaker $\mathrm{C}-\mathrm{H}$ donors for anion binding. When the receptor binds the thiocyanate guest over the strong hydrogenbonding acceptor, its conformation is adapted to accomplish the binding with strong $\mathrm{N}-\mathrm{H}$ donor groups.

\section{Conformational analysis}

In a great extent, crystal structure 3 resembles $1 \mathbf{b}$, except having three methanol molecules per CZ-dimer. Aliphatic chain torsion angle analysis for all conformers shows fine details in conformational adaptability of the receptor for the specific anion (Table 1 and Fig. 3). For both C-conformers in $\mathbf{1 b}$ and 3 , torsion angle values fall within a very narrow angular window. The Z-conformers, roughly, could be divided into two pairs, depending on the distance between the centres of two pyrone rings. More compact ones are almost the same and are used as building blocks in $1 \mathrm{a}$ and 2 nnew polymers of a $[s y n-Z \cdots s y n-Z]_{n}$ type $\}$. The others found in CZ-dimers show significant differences.

Thiocyanate is placed almost parallel to the line defined by the centres of pyrone and RAHB-ring giving rise to aromatic a)

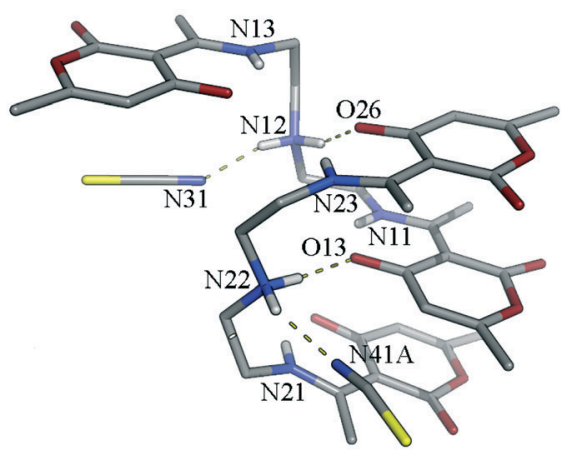

c)

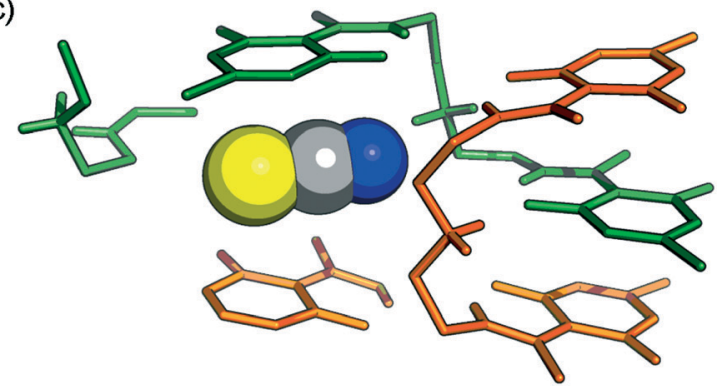

b)

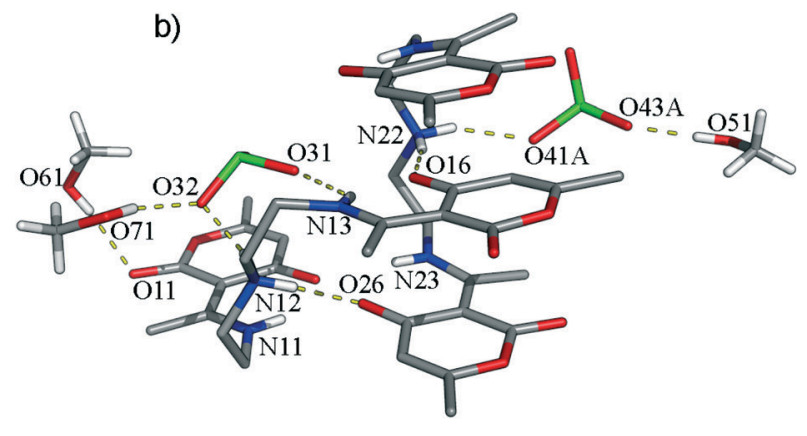

d)

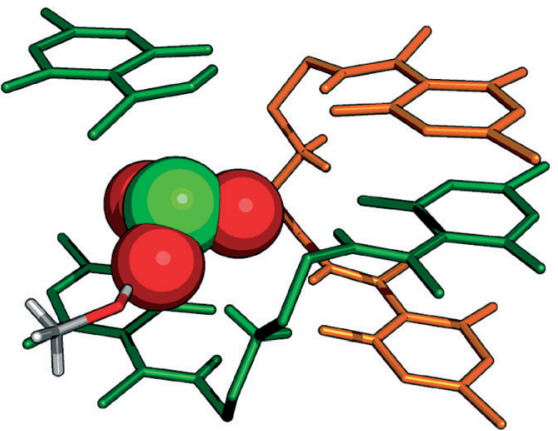

Fig. 2 Hydrogen bonding scheme in $\mathrm{CZ}$-dimers complexing (a) $\mathrm{SCN}^{-}$(1b) and (b) $\mathrm{ClO}_{3}{ }^{-}$(3) anions. A part of the symmetrically related molecules is shown to depict the environment of encapsulated (c) $\mathrm{SCN}^{-}$and (d) $\mathrm{ClO}_{3}{ }^{-}$anions. Hydrogen atoms which are not participating in the hydrogen bonding are omitted for clarity. 


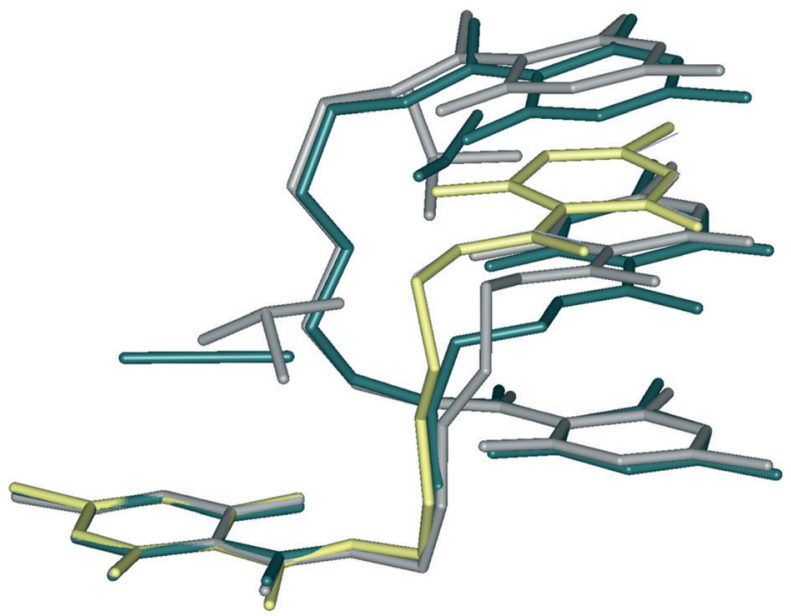

Fig. 3 Overlay of the molecular structures from 1a (yellow), 1b (dark grey), 2 (light blue) and 3 (grey). Hydrogen atoms are not shown.

interactions. Although it is as close to the Z-conformer as $\mathrm{SCN}^{-}, \mathrm{ClO}_{3}^{-}$simply needs more space which causes the slight shift in the upper part of the aliphatic chain (as in Fig. 3) so that "tweezed" pyrone moiety maintains the same position. To encapsulate a pyramidal $\mathrm{ClO}_{3}{ }^{-}$anion, the distance between two Z-conformers must be greater (in 3, it is longer for about $0.3 \AA$ than in 1b). This opening results in an additional space which becomes populated by methanol molecules. Accommodated solvent molecules provide a source of HB-donors for the remaining oxygen atoms of the chlorate. Crystal packing of forms $\mathbf{1 b}$ and 3 are shown in Fig. 4.

\section{Hirshfeld surface analysis}

Differences in the anion environment and the details of intermolecular hydrogen bonding in structures $\mathbf{1 a}, \mathbf{1 b}$ and $\mathbf{3}$ can be extracted from decomposed two-dimensional fingerprint plots. ${ }^{16}$ Scheme 2 shows the contribution (in \%) to the Hirshfeld surface area for a distinct type of intermolecular contact for $\mathrm{SCN}^{-}$and $\mathrm{ClO}_{3}{ }^{-}$anions in the HB-networks 1a, 1b and 3. $\mathrm{S} \cdots \mathrm{H}$ contacts comprise $47.7 \%$ of the surface area in $1 \mathrm{a}$ and $1 \mathrm{~b}$ (Z-conformers) and $30.6 \%$ in $\mathbf{1 b}$ (C-conformer). For C-conformer, the contribution of $\mathrm{N} \cdots \mathrm{H}$ contacts to the total surface area is smaller. This is largely compensated with the increase in the surface area involved in the $\pi \cdots \pi$ interactions. In 3 , anions are mostly connected to the hydrophilic amino and hydroxyl groups. One $\mathrm{ClO}_{3}{ }^{-}$anion is additionally placed between two $\pi$-systems from $\mathrm{HL}^{+}$molecules giving rise to the anion $\cdots \pi$ interactions.

\section{IR spectroscopy}

In the spectra of all complexes, the sharp N-H band at 3123 $\mathrm{cm}^{-1}$ disappears upon complexation, indicating that the central amino group now participates in hydrogen bonding. For 1a, where the $\mathrm{SCN}^{-}$nitrogen atom is an acceptor of the strong hydrogen bond from the methanol hydroxyl group
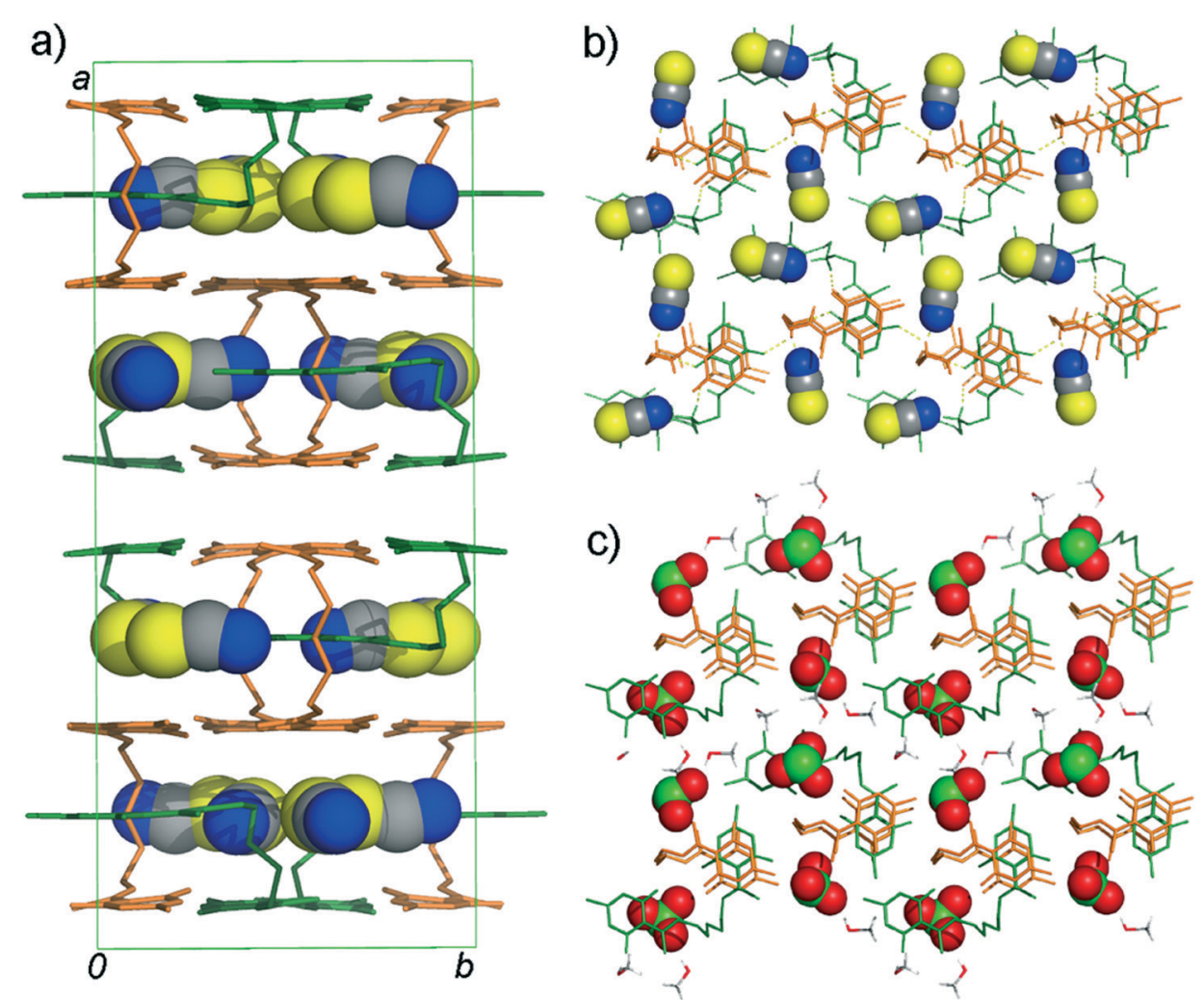

Fig. 4 (a) Crystal packing in $1 \mathrm{~b}$ viewed down the crystallographic c-axis. Layers of CZ-dimers and encapsulated anions viewed down the crystallographic a-axis (b) in $\mathbf{1 b}$ and (c) in 3 . Hydrogen atoms which are not participating in the hydrogen bonding are omitted for clarity. HL and methanol molecules are shown as sticks; anions are shown in the CPK-mode. 


\begin{tabular}{|l|c|c|c|c|}
\hline \multicolumn{2}{|c|}{47.7} & \multicolumn{3}{c|}{32.4} \\
\hline
\end{tabular}

Scheme 2 Relative contributions $(>5 \%)$ to the Hirshfeld surface (for different types of intramolecular contacts: $\mathrm{S}$ or $\mathrm{Cl} \cdots \mathrm{H}$, blue; $\mathrm{N}$ or $\mathrm{O} \cdots \mathrm{H}$, red; $\mathrm{C} \cdots \mathrm{H}$, green; $\mathrm{S}(\mathrm{Cl}) \cdots \mathrm{C}$, purple; $\mathrm{C} \cdots \mathrm{C}$, turquoise; other contacts, orange). The data were derived from the fingerprint plots for $\mathrm{SCN}^{-}$and $\mathrm{ClO}_{3}^{-}$in $\mathrm{HB}$ networks (from top): 1a, $\mathbf{1 b}$ [conformers $\mathrm{C}$ and $\mathrm{Z}$ ] and $\mathbf{3}$ [conformers $\mathrm{C}$ and $\mathrm{Z}$ ].

$\left[\mathrm{O}(\right.$ methanol $) \cdots \mathrm{N}\left(\mathrm{SCN}^{-}\right)$distance is $\left.2.837 \AA\right]$, the band corresponding to $\mathrm{C} \equiv \mathrm{N}$ stretching vibration is a sharp band found at $2054 \mathrm{~cm}^{-1}$. For $1 \mathrm{~b}$, where two crystallographically independent $\mathrm{SCN}^{-}$ions are hydrogen bonded by protonated amino groups of the C- and Z-conformers of the host [with $\mathrm{N}(\mathrm{amino}) \cdots \mathrm{N}\left(\mathrm{SCN}^{-}\right)$distances of $2.698 \AA$ and $2.926 \AA$, respectively], this band can be found at $2053 \mathrm{~cm}^{-1}$ with a wide shoulder around $2037 \mathrm{~cm}^{-1}$. However, regardless of the anion present in the structure, the band pattern in the range of $1700-500 \mathrm{~cm}^{-1}$ depends largely on the specific type of host conformation or supramolecular self-assembly.

1a and 2 (as well as in the HL: $\mathrm{I}^{-}$complex) have almost identical arrangement of the host cations, where HL is exclusively in syn-Z conformation and builds chains along the crystallographic $a$-axis. The lactone oxo-group in these chains is involved in the strong hydrogen bond from the central protonated amino group of the other $\mathrm{HL}$, resulting in the shift of the corresponding band from $1690 \mathrm{~cm}^{-1}$ in $\mathrm{L}$ to $1683 \mathrm{~cm}^{-1}$ in these complexes. In $\mathbf{1 b}$, where the $\mathrm{HL}$ assembles to syn-Csyn- $\mathrm{Z}$ dimer, the same band can be found at $1700 \mathrm{~cm}^{-1}$. Other bands, corresponding to $\mathrm{C}=\mathrm{C}, \mathrm{C}=\mathrm{O}$ and $\mathrm{C}=\mathrm{N}$ vibrations, are found at 1654, 1602, 1571 (broad doublet) and $1480 \mathrm{~cm}^{-1}$ in $1 \mathrm{a}$ and $1 \mathrm{~b}$. In $1 \mathrm{~b}$, these bands are shifted to 1653,1612 , 1569 (sharp singlet) and $1474 \mathrm{~cm}^{-1}$. The band pattern in $\mathbf{1 b}$ was compared to the previously observed complex of HL with hydrogen fumarate, where the HL was assembled in an almost identical syn-C-syn-Z dimer. ${ }^{13}$ The investigated bands in this complex are identical to those from $\mathbf{1 b}$, with slight differences assigned to bonded fumarate (Fig. S1 and S2 $†$ ).

For the $\mathrm{ClO}_{3}{ }^{-}$complex 3, the lactone oxo-group band can be observed at $1699 \mathrm{~cm}^{-1}$, and the IR pattern for $\mathrm{C}=\mathrm{C}, \mathrm{C}=\mathrm{O}$ and $\mathrm{C}=\mathrm{N}$ vibrations resembles that from $1 \mathrm{~b}$. All four characteristic vibration modes for the $\mathrm{ClO}_{3}{ }^{-}$anion are clearly visible in the spectrum, the $\mathrm{Cl}-\mathrm{O}$ symmetric stretch at $939 \mathrm{~cm}^{-1}$ as a moderately strong band, $\mathrm{Cl}-\mathrm{O}$ asymmetric stretch at 980 $\mathrm{cm}^{-1}$ as a broad and strong band, and the "umbrella" vibration at $607 \mathrm{~cm}^{-1}$. The broadening of the signals can be tentatively assigned to the presence of two differently bonded
$\mathrm{ClO}_{3}{ }^{-}$anions in the structure and the overlapping of their vibration bands. The inspection of the infrared spectra for the obtained forms revealed that for these systems this technique could be extremely informative not only for establishing the composition of the supramolecular complex and primary interactions between host and guest on the molecular level ${ }^{19}$ but also for establishing the mode of the folding and self-organization between the HL cations. Each of the observed conformers or supramolecular assembly types of $\mathrm{HL}$ has a unique spectrum. Since the majority of these compounds are air-sensitive solvates, PXRD data are often ambiguous. IR spectra can thus provide a quick insight into the arrangement of the host molecules.

\section{Thermal behaviour}

The solvated form of the thiocyanate complex, 1a, was subjected to DSC and TGA measurements prior to the crystalline methanol loss. The laboratory was cooled to $10{ }^{\circ} \mathrm{C}$ and the crystals in their mother liquid were kept at $4{ }^{\circ} \mathrm{C}$. Crystals of 1a were taken from their mother liquid and immediately dried in methanol vapours, in order to remove methanol from their surface and to prevent egress of methanol from the crystal structure. The prepared sample was placed in 40 $\mu \mathrm{L}$ aluminium crucibles and sealed with a perforated aluminium cover. The DSC curve revealed two thermal events just before $130{ }^{\circ} \mathrm{C}$ which are followed by a stronger endotherm at $190{ }^{\circ} \mathrm{C}$ (melting). We collected a sample at $140{ }^{\circ} \mathrm{C}$ and analysed it by PXRD and IR. No significant changes were observed in IR spectra, and the PXRD diffractogram showed a partial amorphization of the compound. However, no thermally induced transformation of $1 \mathrm{a}$ to $1 \mathrm{~b}$ was observed. Compound 2 showed almost identical thermal behaviour to $1 \mathrm{a}$. Compound 1b was stable below $195{ }^{\circ} \mathrm{C}$ (onset), where the strong endotherm was ascribed to the melting. For complex 3 , no thermal measurements were performed due to its potential explosive properties.

\section{Conclusions}

We have demonstrated how geometrically simple anions such as $\mathrm{SCN}^{-}$and $\mathrm{ClO}_{3}{ }^{-}$can serve as versatile templates for building divergent hydrogen-bonding networks. The complex coordinating potential of these anions arises primarily from their ambivalent hydrogen-bond or $\pi$-accepting properties. Depending on the available anion accepting group (e.g. S- or $\mathrm{N}$-atoms in $\mathrm{SCN}^{-}$), the flexible $\mathrm{HL}$ molecules respond by adopting different conformers or self-organization modes, to provide a rigid and complementary environment for the most efficient binding in the formed crystal architecture. In form 1a, $\mathrm{SCN}^{-}$uses a sulphur atom as an acceptor and all strong hydrogen bond donors of the HL become (coordinatively) saturated by interactions with the oxo-functionalities from other HL molecules, so only the weaker directional binding groups are accessible for anion binding. On the other hand, when $\mathrm{SCN}^{-}$uses a nitrogen atom as a hydrogen-bonding acceptor (form $\mathbf{1 b}$ ), then HL changes its geometry in order to employ 
strong donor groups for optimal binding of $\mathrm{SCN}^{-}$. In terms of number of potential hydrogen bond acceptors, chlorate anion is more demanding. Hydrogen bonding saturation is completed through interaction with solvent molecules in 3 . Although it is hard to expect control over the local geometry in the solid state, the results show how multifaceted anions can be used as complex anionic templates for building new and diverse supramolecular systems.

\section{Experimental}

\section{Materials}

All chemicals (Aldrich) used for the syntheses were at least of analytical grade and used as purchased. Solvents (Kemika) were distilled before use.

\section{General synthetic procedures}

L was synthesized by the method described in the literature. $^{20}$ The purity of the sample was checked by IR and UVvis analyses. Complexes $\mathbf{1 a}, \mathbf{1 b}$ and 2 were obtained by selfassembly processes in the methanol solutions. All syntheses were conducted at room temperature. Complex 1a was prepared by addition of $\mathrm{NH}_{4} \mathrm{SCN}(0.1 \mathrm{mmol})$ to the methanol solution of $\mathrm{L}(0.062 \mathrm{mmol}$ in $4 \mathrm{~mL}$ of methanol) acidified by an equimolar amount of $p$-toluenesulfonic acid (yield, based on $\mathbf{L}=67 \%$ ). Colourless prisms readily lose the crystalline solvent after a short exposure to air. Complex 1b was prepared by an identical procedure with the only difference being that $\mathrm{KSCN}$ was used as a source of $\mathrm{SCN}^{-}$anions (yield $=82 \%$ ). The same product was obtained by reaction of $\mathrm{NH}_{4} \mathrm{SCN}$ and $\mathrm{L}$ in acidified methanol $(0.062 \mathrm{mmol}$ in $2 \mathrm{~mL}$, yield $=76 \%)$ or as a microcrystalline product from EtOH (yield $=90 \%$ ). 1 b crystallizes as colourless plates, which are stable upon exposure to air. Crystals of $\mathbf{1 a}$ and $\mathbf{1 b}$, appropriate for diffraction studies, were obtained from mother liquids. Complex 2 was obtained by addition of an equimolar amount of $\mathrm{HBr}$ to the methanol solution of $\mathbf{L}(0.062 \mathrm{mmol}$ in $2.4 \mathrm{~mL}$ of methanol). Colourless prisms were obtained after the solution was left to stand for 1 day at room temperature (87\%). Crystals appropriate for diffraction studies were collected from diluted methanol solution $(0.062 \mathrm{mmol}$ of starting compounds in $8 \mathrm{~mL}$ of methanol). The iodide complex was obtained by reaction of equimolar amounts of $\mathbf{L}$ and tetrabutylammonium iodide in acidified methanol solution $(0.062 \mathrm{mmol}$ of $p$-toluenesulfonic acid in $3 \mathrm{~mL}$ of methanol). Complex 3 was obtained by the following procedure: $\mathrm{Ba}\left(\mathrm{ClO}_{3}\right)_{2}(0.040 \mathrm{mmol})$ was dissolved in $3 \mathrm{~mL}$ of methanol, and sulphuric acid $(0.07 \mathrm{mmol})$ was added to the reaction mixture. The white precipitate $\left(\mathrm{BaSO}_{4}\right)$ was filtered. Then, $0.062 \mathrm{mmol}$ of $\mathbf{L}$ was dissolved in $3 \mathrm{~mL}$ of methanol and was added to the clear filtrate. The colourless crystals, which would decompose when dried, were obtained from their mother liquid after the solution was left to stand for 7 days at RT (yield $=37 \%$ ). The crystals were suitable for diffraction studies.

\section{IR spectroscopy}

IR spectra were recorded on a PerkinElmer Spectrum RXI FTIR spectrometer ( $\mathrm{KCl}$ pellet technique, 4000-400 $\mathrm{cm}^{-1}$ range, $2 \mathrm{~cm}^{-1}$ step). L: 3432 (broad) ( $\left.v_{\mathrm{N}-\mathrm{H}}, \mathrm{RAHB}\right) ; 3366$ (sharp) $\left(v_{\mathrm{N}-\mathrm{H}}\right.$, central) 1688, 1656, 1636, 1574, 1472 (all $v \mathrm{~s}$, mixed $\mathrm{C}=\mathrm{O}$, $\mathrm{C}=\mathrm{C})$. 1a: 3466, 3353 (br) ( $v_{\mathrm{N}-\mathrm{H}}$, hydrogen bonded); 2052 $\left(v_{\mathrm{C}} \equiv \mathrm{N}\right) ; 1682,1652,1601,1571$ (all $v \mathrm{~s}$, mixed $\mathrm{C}-\mathrm{O}, \mathrm{C}=\mathrm{C}$ ). 1b: 3440 (br) ( $v_{\mathrm{N}-\mathrm{H}}$, hydrogen bonded); $2053\left(v_{\mathrm{C} \equiv \mathrm{N}}\right) ; 1700,1655$, 1612, 1567 (all $v \mathrm{~s}$, mixed $\mathrm{C}-\mathrm{O}, \mathrm{C}=\mathrm{C}) \cdot 2$ : 3440 (br) $\left(v_{\mathrm{N}-\mathrm{H}}\right.$, hydrogen bonded); 1676, 1640, 1576 (all vs, mixed C-O, $\mathrm{C}=\mathrm{C}), 843(\mathrm{~s})\left(v_{\mathrm{P}-\mathrm{F}}\right)$.

\section{TGA and DSC experiments}

Thermogravimetric analyses were performed using a MettlerToledo TGA/SDTA851e thermobalance with aluminium crucibles under nitrogen stream with a heating rate of $5^{\circ} \mathrm{C} \mathrm{min}^{-1}$. The results were processed using the Mettler STARe 9.01 software. DSC measurements were performed under a nitrogen stream using a Mettler-Toledo DSC823e calorimeter with STARe SW $9.01\left(5^{\circ} \mathrm{C} \mathrm{min}^{-1}\right)$.

\section{Single-crystal X-ray crystallography}

Compounds 1a, 1b, 2 and 3 were obtained from methanol as colourless prismatic crystals at room temperature (Table 2). Each single crystal was mounted on a glass fibre and used for measurements of unit cell parameters and intensity data collection. Diffracted intensities were collected using an Oxford Diffraction Xcalibur 3 CCD diffractometer with graphitemonochromated MoK $\alpha(0.71073 \AA)$ radiation at 120, 150 and $293 \mathrm{~K}$. The CrysAlis ${ }^{21}$ program package was used for data collection, cell refinement and data reduction. Multi-scan empirical absorption corrections were applied using spherical harmonics, implemented in SCALE3 ABSPACK scaling algorithm of CrysAlis. Structures were solved by direct methods $\left(\mathrm{SHELXS}^{22}\right)$ and refined with full-matrix least-squares on $F^{2}$ (SHELXL-97 ${ }^{22}$ and $2014^{22 b, c}$ ), using the WinGX ${ }^{23}$ program package. All non-hydrogen atoms were refined anisotropically. All hydrogen atoms were assigned calculated positions and allowed to ride on their carrier atoms. There are two versions of structure 2 , one with modelled disordered molecules (presented only in the ESI $\dagger$ ) and the other one in which the electron contribution of the non-modelled molecules was subtracted from the diffraction data using the PLATON/ SQUEEZE $^{24}$ procedure. The non-modelled molecules were found to occupy $297 \AA^{3}$ or $22 \%$ of the unit cell. A summary of crystal data is presented in Table 2. Programs PLATON ${ }^{24}$ and PyMOL were used for analysis of the structure and drawing preparation. Supplementary crystallographic data sets for structures 1a, 1b, 2 (squeezed) and 3 are available through the Cambridge Structural Database with deposition numbers 978263-978265 and 1035947. The second, non-squeezed model of the $\mathrm{HL}: \mathrm{Br}^{-}$complex is available by quoting CCDC number 1051952. 


\section{Structural data studies}

The study of the thiocyanate complexation modes using selected structural criteria was conducted using the Cambridge Structural Database (CSD 5.24 + 2 updates) for small molecules and Protein Data Bank (PDB) for macromolecules. The obtained data are compared and discussed in terms of geometrical features of our system structures. The available data for chlorate were insufficient to make a reliable conclusion.

\section{CSD search}

The analysis of the $\mathrm{SCN}^{-}$geometry in supramolecular complexes provided a main set of 238 structures that satisfied the given criteria (3D coordinates determined, not disordered, no errors, not covalently bound or coordinated to the metal ions, not polymeric and with $R$-factor $<0.075$; bond lengths and angles were constrained to 1.00-1.25 $\AA$ for $\mathrm{C}-\mathrm{N}$ distance, 1.50-1.75 Å for C-S distance and $170-180^{\circ}$ for $\mathrm{S}-\mathrm{C}-\mathrm{N}$ angle), among 85 structures that did not contain metal ions. Considering the importance of $\mathrm{SCN}^{-}$, it is a surprisingly low number of structures, suggesting information deficiency about precise coordinative properties of this ambivalent ion. ${ }^{7}$ The analyzed hydrogen bonds included $\mathrm{N}, \mathrm{O}$ and $\mathrm{C}$ atoms as donors and $\mathrm{S}$ or $\mathrm{N}\left(\mathrm{SCN}^{-}\right)$atoms as acceptors. In the selected set, 114 structures contained at least one $\mathrm{N}-\mathrm{H}$ donor group and 92 structures with at least one $\mathrm{O}-\mathrm{H}$ group. The distances between $\mathrm{O}$ and $\mathrm{N}$ donor atoms and $\mathrm{N}\left(\mathrm{SCN}^{-}\right)$atom were limited to $3.6 \AA$ $[\mathrm{C}($ donor $) \cdots \mathrm{N}$ distance is limited to $3.95 \AA]$ and distances between donor atoms and $\mathrm{S}\left(\mathrm{SCN}^{-}\right)$atom were limited to $3.9 \AA$ (except for the $\mathrm{C}-\mathrm{H} \cdots \mathrm{S}$ bond where the $\mathrm{C} \cdots \mathrm{S}$ distance was limited to $4.0 \AA$ ).

In all cases, the hydrogen bond angle was in the $90-180^{\circ}$ range. In the main set, the $\mathrm{N}\left(\mathrm{SCN}^{-}\right)$atom was identified as a hydrogen-bonding acceptor in 174 structures. However, in many structures, these interactions overlap and there is a combination of more than one donor group (in 88 cases, the $\mathrm{N}-\mathrm{H}$ group acts as a donor; 48 structures with the $\mathrm{O}-\mathrm{H}$ donor group; 120 structures with the $\mathrm{C}-\mathrm{H}$ donor group). $\mathrm{C}-\mathrm{H}$ is an exclusive donor for $\mathrm{N}\left(\mathrm{SCN}^{-}\right)$in 46 (of 120) structures, but only in the structures where no $\mathrm{N}-\mathrm{H}$ donor group is present. A combination of $\mathrm{N}-\mathrm{H}$ and $\mathrm{C}-\mathrm{H}$ donors with a $\mathrm{N}\left(\mathrm{SCN}^{-}\right)$acceptor atom is present in 82 structures and in combination with $\mathrm{O}-\mathrm{H}$ group in 5 structures. Combination of $\mathrm{O}-\mathrm{H}$ and $\mathrm{C}-\mathrm{H}$ donor groups is present in 19 structures. Out of 177 structures, where $\mathrm{X}-\mathrm{H} \cdots \mathrm{SCN}{ }^{-}$hydrogen bond is observed $(\mathrm{X}=\mathrm{N}$, $\mathrm{O}$ or $\mathrm{C}$ atom), in 108 of 149 of them $\mathrm{C}-\mathrm{H}$ group is an exclusive donor. In only 60 structures, the donor group for $\mathrm{S}\left(\mathrm{SCN}^{-}\right)$ atom is the $\mathrm{N}-\mathrm{H}$ group, and in 23 structures, the donor role was given to the $\mathrm{O}-\mathrm{H}$ group.

Thiocyanate is a known bridging ligand, with $\mathrm{N}$ and $\mathrm{S}$ groups serving as a donor for coordination to metal cations, resulting in polynuclear coordination compounds. In previous analyses of coordinative abilities of the $\mathrm{SCN}^{-}$anion, the possibility of $\mathrm{SCN}^{-}$as $\mathrm{S}, \mathrm{N}$ chelating ligand was suggested. ${ }^{7}$ However, by inspecting the data in our research, no evidence of the chelating $\mathrm{S}, \mathrm{N}$ donors were found, but many of the structures in our search contain $\mathrm{SCN}^{-}$as a bridging ligand, simultaneously accepting hydrogen bonds by $\mathrm{S}$ and $\mathrm{N}$ terminal atoms. It could be concluded that the N-terminal side of thiocyanate is in favour of stronger hydrogen-bonding donors, while the S-terminal side is in favour of more hydrophobic interactions with $\mathrm{C}-\mathrm{H}$ donors. Although simple in geometry and relatively small, this anionic species is far from being a simple building block in the crystal structure architecture.

\section{PDB search}

Binding properties of thiocyanate anions in the structures of biological macromolecules were retrieved from the Protein Data Bank. It was found that 217 records contain at least one $\mathrm{SCN}^{-}$molecule per asymmetric unit, out of which 24 structures (with $41 \mathrm{SCN}^{-}$ions present) were determined using X-ray diffraction with a resolution above $1.5 \AA$. A set of 34 free thiocyanate ions, not bound to the metal centres, was used for the interaction analysis. RCSB Ligand explorer $^{17}$ v4.1.0 was used to visualize the interactions and to determine distances between the $\mathrm{SCN}^{-}$ion and the surrounding amino acids/ions/molecules that are within the $4 \AA$ range. The thresholds were as follows: $3.3 \AA$ for the hydrogen bonding interactions, $3.9 \AA$ for the hydrophobic interactions, $3.3 \AA$ for the bridging hydrogen bonding interactions, and $3.5 \AA$ for the metal interactions.

In the vast majority of $\mathrm{SCN}^{-}$ions (28), a nitrogen atom was found as an acceptor of strong hydrogen bond donors, water molecules (27 interactions of the $\mathrm{N} \cdots \mathrm{H}-\mathrm{O}-\mathrm{H}$ type) or amide hydrogen atom (12 interactions of the $\mathrm{N} \cdots \mathrm{H}-\mathrm{N}$ type). A total of 47 interactions with the $\mathrm{C}$ atom ( $\pi$-system) was observed in 29 ions: 44 of the $\mathrm{C}-\mathrm{H} \cdots \mathrm{C}(\pi)$ type and 3 of $\mathrm{C}(\pi) \cdots \mathrm{C}(\pi)$ type. The remaining ions did not satisfy the threshold range. The sulphur atom binding pocket chemical character was inspected manually in PyMOL. ${ }^{18}$ In 31 of 34 $\mathrm{SCN}^{-}$ions, the sulphur atom preferred hydrophobic pockets (22 were exclusively hydrophobic), while in only three ions exclusively hydrophilic interactions were observed. The thiocyanate binding behaviour/preference in small molecule crystal structures and that in macromolecule crystal structures are in good agreement. The results of this analysis can offer assistance in thiocyanate modelling in macromolecules.

\section{Acknowledgements}

The authors thank the Ministry of Science, Education and Sports of the Republic of Croatia for financial support (grant numbers 119-1191342-1082 and 119-1193079-1084). We are grateful to Prof. Dubravka Matković-Čalogović, Dr. Mirta Rubčić and Mrs. Mia Vrbanac Užarević for critical discussions.

\section{Notes and references}

1 (a) P. A. Gale, Chem. Soc. Rev., 2010, 39, 3746-3771; (b) A. Basu and G. Das, Dalton Trans., 2012, 41, 10792-10802; (c) A. Basu and G. Das, Chem. Commun., 2013, 49, 3997-3999; (d) L. Trembleau, T. A. D. Smith and M. H. Abdelrahman, Chem. 
Commun., 2013, 49, 5850-5852; (e) R. Custelcean, Chem. Soc. Rev., 2010, 39, 3675-3685.

2 (a) P. D. Beer and P. A. Gale, Angew. Chem., Int. Ed., 2001, 40, 486-516; (b) F. P. Schmidtchen, Chem. Soc. Rev., 2010, 39, 3916-3935; (c) F. P. Schmidtchen and M. Berger, Chem. Rev., 1997, 97, 1609-1646; (d) R. Vilar, Struct. Bonding, 2008, 129, 175-206; (e) F. P. Schmidtchen, Top. Curr. Chem., 2005, 255, 1-29; $(f)$ R. Custelcean and P. Remy, Cryst. Growth Des., 2009, 9, 1985-1989.

3 (a) R. Vilar, Angew. Chem., Int. Ed., 2003, 42, 1460-1477; (b) N. Gimeno and R. Vilar, Coord. Chem. Rev., 2006, 250, 3161-3189; (c) M. H. Filby and J. W. Steed, Coord. Chem. Rev., 2006, 250, 3200-3218; (d) M. R. Sambrook, P. D. Beer, J. A. Wisner, R. L. Paul and A. R. Cowley, J. Am. Chem. Soc., 2004, 126, 15364-15365; (e) M. D. Lankshear and P. D. Beer, Acc. Chem. Res., 2007, 40, 657-668; $(f)$ R. Sekiya, M. Fukuda and R. Kuroda, J. Am. Chem. Soc., 2012, 134, 10987-10997.

4 K. Ariga and T. Kunitake, Supramolecular Chemistry Fundamentals and Applications, Springer-Verlag, Berlin, Heidelberg, 2006.

5 (a) A. P. Umali, S. E. LeBouef, R. W. Newberry, S. Kim, L. Tran, W. A. Rome, T. Tian, D. Taing, J. Hong, M. Kwan, H. Heymann and E. V. Anslyn, Chem. Sci., 2011, 2, 439-445; (b) A. T. Wright and E. A. Anslyn, Chem. Soc. Rev., 2006, 35, 14-28.

6 R. Custelcean, Chem. Commun., 2013, 49, 2173-2182.

7 (a) L. Tchertanov and C. Pascard, Acta Crystallogr., Sect. B: Struct. Sci., 1996, 52, 685-690; (b) L. Tchertanov, Supramol. Chem., 2000, 12, 67-91.

8 (a) M. Kabešová, R. Boča, M. Melník, D. Valigura and M. Dunaj-Jurčo, Coord. Chem. Rev., 1995, 140, 115-135; (b) D. A. Buckingham, Coord. Chem. Rev., 1994, 135-136, 587-621.

9 (a) H. Zhang, X. Wang, K. Zhang and B. K. Teo, Coord. Chem. Rev., 1999, 183, 157-195; (b) L. Li, L. Zhu, Z.-C. Yue, W.-L. Zhang, B. Zhang, Y.-Y. Niu and H.-W. Hou, CrystEngComm, 2013, 15, 8395-8399; (c) R. Custelcean, Chem. Commun., 2013, 49, 2173-2182.

10 Y. Inokuma, S. Yoshioka, J. Ariyoshi, T. Arai, Y. Hitora, K. Takada, S. Matsunaga, K. Rissanen and M. Fujita, Nature, 2013, 495, 461-466.
11 K. Užarević, I. Đilović, D. Matković-Čalogović, D. Šišak and M. Cindrić, Angew. Chem., Int. Ed., 2008, 47, $7022-7025$.

12 (a) K. Užarević, I. Đilović, N. Bregović, V. Tomišić, D. Matković-Čalogović and M. Cindrić, Chem. - Eur. J., 2011, 17, 10889-10897; (b) N. Bregović, N. Cindro, L. Frkanec, K. Užarević and V. Tomišić, Chem. - Eur. J., 2014, 20, 15863-15871.

13 K. Užarević, I. Halasz, I. Đilović, N. Bregović, M. Rubčić, D. Matković-Čalogović and V. Tomišić, Angew. Chem., Int. Ed., 2013, 52, 5504-5508.

14 F. H. Allen, Acta Crystallogr., Sect. B: Struct. Sci., 2002, 58, 380-388.

15 H. M. Berman, J. Westbrook, Z. Feng, G. Gilliland, T. N. Bhat, H. Weissig, I. N. Shindyalov and P. E. Bourne, Nucleic Acids Res., 2000, 28, 235-242.

16 M. A. Spackman and D. Jayatilaka, CrystEngComm, 2009, 11, 19-32.

17 J. L. Moreland, A. Gramada, O. V. Buzko, Q. Zhang and P. E. Bourne, BMC Bioinf., 2005, 6, 21.

18 The PyMOL Version 0.99rc6 Schrödinger, 2006 DeLano Scientific LLC.

19 A. Mukherjee, S. Tothadi, S. Chakraborty, S. Ganguly and G. R. Desiraju, CrystEngComm, 2013, 15, 4640-4654.

20 (a) S. Liu, S. J. Rettig and C. Orvig, Inorg. Chem., 1991, 30, 4915-4919; (b) P. Gilli, V. Bertolasi, V. Ferretti and G. Gilli, J. Am. Chem. Soc., 2000, 122, 10405-10417.

21 Oxford Diffraction, CrysAlis Software System, Version 1.171.31, 2006.

22 (a) G. M. Sheldrick, Acta Crystallogr., Sect. A: Found. Crystallogr., 2008, 64, 112-122; (b) G. M. Sheldrick, SHELXS2014, Program for Crystal Structure Solution, University of Göttingen, 2014; (c) G. M. Sheldrick, SHELXL, Version 2014/7, Program for Crystal Structure Refinement, University of Göttingen, 2014.

23 L. J. Farrugia, J. Appl. Crystallogr., 1999, 32, 837.

24 (a) P. van der Sluis and A. L. Spek, Acta Crystallogr., Sect. A: Found. Crystallogr., 1990, 46, 194; (b) A. L. Spek, J. Appl. Crystallogr., 2003, 36, 7. 